
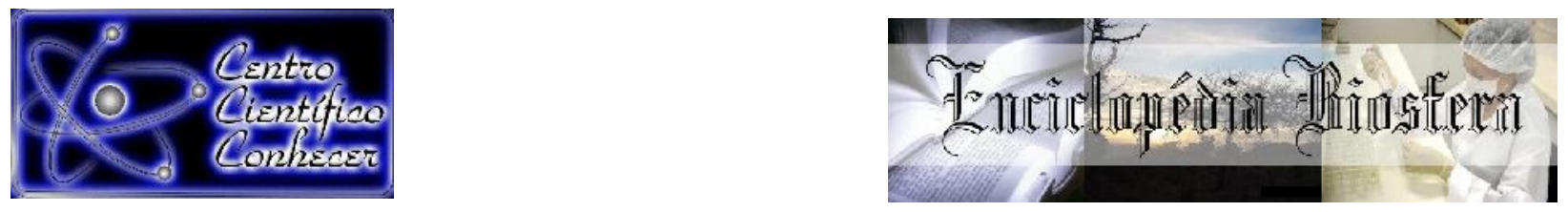

\title{
BEM ESTAR DE SUÍNOS NO MANEJO PRÉ-ABATE EM UM ABATEDOURO- FRIGORÍFICO DO TRIÂNGULO MINEIRO, MINAS GERAIS, BRASIL
}

Italo Moura Ribeiro ${ }^{1}$, Larissa Ferreira Mamede ${ }^{1}$, Igor Carrijo Fernandes de Araújoㄹ, Larissa Mendonça Vieira ${ }^{1}$, Kênia de Fátima Carrijo ${ }^{2}$

1 Médicos Veterinários graduados pela Universidade Federal de Uberlândia Uberlândia-MG, Brasil.

2 Professora Doutora da Universidade Federal de Uberlândia

(keniafcarrijo@yahoo.com.br)

Recebido em: 04/10/2019 - Aprovado em: 30/11/2019 - Publicado em: 15/12/2019

DOI: 10.18677/EnciBio 2019B62

\begin{abstract}
RESUMO
O manejo pré-abate realizado incorretamente e que não preconiza o bem-estar dos animais pode gerar como consequência do estresse, carnes do tipo DFD (escura, dura e seca) e PSE (pálida, mole e exsudativa), diminuindo a lucratividade. Objetivou-se com o presente trabalho verificar as condições de manejo pré-abate (chegada e permanência nas áreas de descanso; condução para a sala de abate) de suínos em um abatedouro-frigorífico localizado no Triângulo Mineiro, a fim de constatar as condições em que estes animais foram submetidos. Foram avaliados 30 lotes de suínos machos e fêmeas, totalizando 5.389 animais. Os dados referentes à pesquisa foram coletados, a partir de observação in loco, avaliando-se os seguintes parâmetros: manejo no desembarque, densidade das pocilgas de descanso e disponibilidade de água aos animais, tempo de descanso e conforto térmico, e uso do bastão elétrico, utilizando metodologia descrita no Manual de Abate Humanitário de suínos da Sociedade Mundial de Proteção Animal (WSPA). Os dados foram avaliados por meio da estatística descritiva. No desembarque, o bastão elétrico foi usado em todos os lotes avaliados, a densidade nas pocilgas de descanso estava adequada, 96,67\% dos lotes tinham disponibilidade de água limpa em quantidade recomendada. Havia apenas sombreamento nas áreas de descanso para conforto térmico dos animais e $72,13 \%$ dos animais eram conduzidos com bastão elétrico quando negavam movimentar-se. As condições de manejo pré-abate analisadas revelaram-se satisfatórias, no entanto deve-se reduzir o uso excessivo do bastão elétrico, bem como a adoção de equipamentos de nebulização e ventilação, para menor estresse dos animais.
\end{abstract}

PALAVRAS-CHAVE: ante-mortem, carne suína, estresse, qualidade de carne 


\title{
PIGS WELFARE IN PRE-SLAUGHTER MANAGEMENT IN SLAUGHTERHOUSE OF TRIÂNGULO MINEIRO, MINAS GERAIS, BRAZIL
}

\begin{abstract}
Incorrect pre-slaughter management without animal welfare can result in stress, DFD (dark, hard and dry) and PSE (pale, soft and exudative) meat, reducing profitability. This study aim is to verify the pre-slaughter management conditions (arrival and permanence in the resting areas; leading to slaughter room) of pigs in a slaughterhouse located in Triângulo Mineiro, in order to verify the conditions that these animals were submitted to. Thirty groups of male and female pigs were evaluated, totaling 5,389 animals. Research data were collected from in loco observation, evaluating the following parameters: landing management, resting pigsties density and water availability to the animals, resting time and thermal comfort, and use of electric pole using the methodology described in Pigs Humanitarian Slaughter Manual of World Animal Protection Society (WSPA). Data were evaluated using descriptive statistics. On landing, electric pole was used in $100 \%$ of groups evaluated, density in the resting pigsties was adequate, $96.67 \%$ of all groups had clean water available in recommended quantity. There was only shading in rest areas for pigs thermal comfort and $72.13 \%$ of the animals were leading with electric pole when they refused to move. The pre-slaughter management conditions analyzed were satisfactory however, the excessive use of electric pole should be reduced, and implementation of misting and ventilation equipment should be considered to reduce animal stress.
\end{abstract}

KEYWORDS: stress, ante-mortem, meat quality, pig meat

\section{INTRODUÇÃO}

A preocupação com o bem-estar dos animais tem impulsionado pesquisas sobre ações que influenciam o estado físico e emocional e consequentemente a qualidade de vida (WEBSTER, 2003). A Organização Mundial de Saúde Animal (OIE) interpreta o bem-estar como a forma que o animal lida com as condições do ambiente em que está inserido. Um animal em condições corretas de bem-estar encontra-se sadio, sem dor, livre de doenças, de estresse e medo, de fome e sede, com acesso a uma dieta que corresponde às suas exigências fisiológicas, e água de qualidade. Além de sentir-se confortável e seguro em um ambiente que possua abrigo com área de descanso e que o possibilite expressar comportamentos normais inerentes de sua espécie (OIE, 2014).

Se algum desses aspectos for negligenciado, principalmente no período préabate dos animais, a qualidade da carne obtida poderá estar comprometida (HOCQUETTE et al., 2014), sendo que esta é considerada uma das maiores preocupações da indústria, frente aos consumidores cada vez mais exigentes. Desta forma, o bem estar influencia não só na maneira como os animais são tratados, mas nas interações de fatores intrínsecos e extrínsecos que definem a qualidade da carne (MOURA et al., 2015).

A genética, idade, sexo e peso são fatores intrínsecos que influenciam diretamente na característica da carne. Quanto aos fatores extrínsecos, destaca-se o manejo pré-abate que engloba desde o embarque até a insensibilização destes para a sangria. Segundo Sionek e Przybylski (2016), se o manejo for feito 
incorretamente pode influenciar em até $40 \%$ dos problemas que trazem consequentemente má qualidade da carne.

O jejum pré-abate é de suma importância no ciclo de produção (DALLA COSTA; DALLA COSTA, 2014), sendo que este diminui o volume do conteúdo estomacal, o que reduz a contaminação da carcaça e consequentemente melhora a segurança alimentar. Porém, um tempo de jejum prolongado traz consequências negativas como o aumento da agressividade dos suínos e queda do rendimento da carcaça (DALLA COSTA et al. 2008; BISPO et al. 2016).

Quanto à condução dos suínos, recomenda-se o uso de chocalhos para estimular a movimentação dos animais com o barulho e se necessário, o contato leve no flanco dos animais, evitando-se a utilização de choques elétricos que acarretam lesões, alto teor de lactato no plasma e aumento do valor de $\mathrm{pH}$ final (CORREA et al.; 2010; DALLA COSTA et al., 2013).

Durante o transporte, os animais enfrentarão diversos fatores estressantes como distância da viagem, densidade animal, trepidações e tipo de condução, modelo de piso e camas, jejum e abstinência de água ou ainda oscilações de temperatura (DALLA COSTA; DALLA COSTA, 2014). Em relação à densidade animal, quando calculada corretamente, diminui o número de mortes e a perda de qualidade da carne, pelo fato de que tanto o excesso quanto a falta de espaço podem causar escoriações de pele, fraturas e mortes. Quanto ao tipo de condução, o motorista deve ter o conhecimento de boas práticas de transporte que garantam o bem-estar dos suínos, com atenção para que nada afete negativamente esse bemestar (LUDTKE et al., 2016a).

Quando o manejo pré-abate é realizado de forma incorreta, anomalias como a carne PSE (pálida, flácida e exsudativa) e DFD (escura, dura e seca) são frequentemente registradas, o que resultam constantemente em condenação de carcaças (FAUCITANO; ROCHA, 2016).

O tempo de descanso no abatedouro também acarreta diferentes níveis de estresse em suínos. Animais que não tiveram período de descanso, manifestam maiores proporções de carcaças com problema de PSE, pois há acidificação dos músculos causada pela ligeira mudança das reservas de glicogênio muscular em ácido láctico, o que resulta em pH diminuído (inferior a 6) em 24 horas, menor capacidade de retenção de água, além de coloração pálida e textura flácida (BISPO et al., 2016).

Em relação ao tempo de descanso prolongado há um aumento na ocorrência de carcaças com o defeito DFD que ocorrem devido a queda no nível de glicogênio que altera a acidificação padrão do músculo post mortem, que terá um valor de pH final superior a 6 . Assim haverá escassa desnaturação das proteínas e a capacidade de retenção de água permanece inalterada, acarretando em uma carne seca e também de coloração mais escura, por absorver a luz e não refleti-la (FELíclO, 1986; LENGERKEN et al., 2002).

De maneira geral a carne PSE e DFD são consequências de fatores estressantes a que os suínos foram submetidos no pré-abate e durante o abate. $A$ Diferença é que a carne PSE surge frequentemente em casos de estresse agudo, ou seja, intenso e pouco antes do abate, e a carne DFD quando há um estresse prolongado (LUDTKE et al., 2016b).

Perante todos os fatores anteriormente citados, observa-se que as condições do manejo pré-abate são determinantes para a qualidade final da carne suína, visto que melhorias nesta etapa da cadeia produtiva resultam no aumento do bem-estar 
desses animais. Diante do exposto, objetivou-se com o presente trabalho verificar as condições de manejo pré-abate, sendo a chegada e permanência nas áreas de descanso, além da condução para a sala de abate de suínos em um abatedourofrigorífico localizado no Triângulo Mineiro, os elementos observados, a fim de constatar as condições que estes animais foram submetidos.

\section{Local}

\section{MATERIAL E MÉTODOS}

A pesquisa foi realizada em um abatedouro-frigorífico sob Inspeção Oficial, destinado ao abate de suínos, situado no Triângulo Mineiro, Minas Gerais, Brasil, com capacidade diária de abate de 440 animais.

Foram avaliados neste estabelecimento, entre os meses de setembro a novembro de 2016, 30 lotes de suínos, machos e fêmeas, procedentes da Mesorregião do Triângulo Mineiro e Alto Paranaíba, com idade mínima de 150 dias totalizando 5.389 animais. Os dados referentes à pesquisa foram coletados, a partir de observação in loco de pontos críticos no manejo ante mortem dos suínos.

\section{Procedimento de análise}

Foi utilizado um formulário padronizado, do tipo check-list (Figura 1), baseado na planilha de auditoria "Voogd Consulting Inc." e "AMI Foundation", proposta pela pesquisadora Temple Grandin (AMI FOUNDATION, 2010), com alterações, cuja metodologia esta descrita no Manual de Abate Humanitário de suínos, da WSPA (LUDTKE et al., 2010a).

Os principais parâmetros avaliados foram: manejo no desembarque, densidade das pocilgas de descanso e disponibilidade de água aos animais, tempo de descanso e conforto térmico, e uso do bastão elétrico durante o desembarque e na entrada do restrainer. Esta metodologia é recomendada pela Sociedade Mundial de Proteção Animal (WSPA) e adotada em auditorias de bem estar animal, aplicadas em abatedouros-frigoríficos de suínos.

\section{Análise dos dados}

Após as observações in loco, as informações obtidas foram registradas no referido formulário, posteriormente digitadas em um banco de dados e interpretadas por meio de análise descritiva, obtendo-se frequências e percentuais dos pontos críticos no manejo pré-abate de suínos. Os resultados foram apresentados em tabelas. 


\section{AUDITORIA DE BEM-ESTAR ANIMAL}

Empresa:

Auditor:
Data: $\mathrm{N}^{\circ}$ de animais abatidos/hora:

Marcar Conforme (C), Conforme com restrição (CR), não conforme (NC), e não conformidade grave (G) no quadro abaixo:

\begin{tabular}{|c|c|c|c|c|c|c|c|c|c|c|}
\hline \multirow{2}{*}{$\begin{array}{c}\text { PC 1: TRANSPORTE E } \\
\text { DESEMBARQUE }\end{array}$} & \multicolumn{10}{|c|}{$\begin{array}{lccc}\begin{array}{l}\text { Avaliação dos veículos que } \\
\text { desembarcados no dia da auditoria. }\end{array} & \\
\end{array}$} \\
\hline & V1 & V2 & V3 & V4 & V5 & V6 & V7 & V8 & V9 & V10 \\
\hline \multicolumn{11}{|l|}{ A densidade do veículo está adequada? } \\
\hline \multicolumn{11}{|l|}{$\begin{array}{l}\text { O veículo está estacionado corretamente de } \\
\text { modo a não deixar espaço (vão) entre a rampa } \\
\text { do desembarque e o compartimento de carga? }\end{array}$} \\
\hline \multicolumn{11}{|l|}{$\begin{array}{l}\text { Os suinos foram desembarcados logo à } \\
\text { chegada do frigorifico? }\end{array}$} \\
\hline \multicolumn{11}{|l|}{$\begin{array}{l}\text { Os suinos desembarcaram do frigorífico com } \\
\text { calma? A abertura dos portões dos } \\
\text { compartimentos foi realizada de forma } \\
\text { sincronizada com a descida dos suinos? }\end{array}$} \\
\hline \multicolumn{11}{|l|}{$\begin{array}{l}\text { Os suinos foram desembarcados com auxilios } \\
\text { de manejos que não provoquem dor ou lesões? }\end{array}$} \\
\hline \multicolumn{11}{|l|}{$\begin{array}{l}\text { Há registro de mortalidade no transporte com } \\
\text { as atribuições das causas? }\end{array}$} \\
\hline \multicolumn{11}{|l|}{$\begin{array}{l}\text { Há manutenção adequada dos compartimentos } \\
\text { do veículo ou da rampa de desembarque sem } \\
\text { presença de objetos pontiagudos ou cortantes } \\
\text { que possam ferir os suinos? }\end{array}$} \\
\hline PCC 1: ABATE EMERGENCIAL & \multicolumn{10}{|c|}{$\begin{array}{l}\text { Avaliar nas instalações de desembarque e área de } \\
\text { descanso do frigorifico. }\end{array}$} \\
\hline \multicolumn{11}{|c|}{$\begin{array}{l}\text { Suinos incapacitados de andar com sinais de } \\
\text { sofrimento foram submetidos ao abate de } \\
\text { emergência imediata? E considerado não } \\
\text { conformidade grave e falha nesse } \\
\text { procedimento. }\end{array}$} \\
\hline \multicolumn{11}{|l|}{$\begin{array}{l}\text { A remoção de suínos incapacitados de andar } \\
\text { foi realizada com auxilio de métodos } \\
\text { humanitários, sem arraste? }\end{array}$} \\
\hline $\begin{array}{l}\text { PC 3: DENSIDADE DAS } \\
\text { POCILGAS DE DESCANSO }\end{array}$ & \multicolumn{10}{|c|}{ Avaliar nas pocilgas de descanso do frigorífico. } \\
\hline \multicolumn{11}{|l|}{$\begin{array}{l}\text { Há espaço suficiente nas pocilgas para que } \\
\text { todos os suinos deitem ao mesmo tempo e } \\
\text { possam caminhar e ter acesso a água? }\end{array}$} \\
\hline PC 4: DISPONIBILIDADE DE ÁGUA & Ava & iar $r$ & sp & ocilg & as de & des & :anso & dof & rigorí & fico. \\
\hline \multicolumn{11}{|l|}{$\begin{array}{l}\text { Há água limpa e disponível para permitir que } \\
\text { pelo menos } 15 \% \text { dos suínos tenham acesso } \\
\text { simultâneo ao bebedouro? }\end{array}$} \\
\hline $\begin{array}{c}\text { PC 5: TEMPO DE DESCANSO E } \\
\text { CONFORTO TÉRMICO }\end{array}$ & \multicolumn{10}{|c|}{ Avaliar nas pocilgas de descanso do frigorífico. } \\
\hline \multicolumn{11}{|l|}{$\begin{array}{l}\text { O ambiente da área de descanso promove } \\
\text { conforto térmico aos suínos? Há } \\
\text { sombreamento, ventilação e nebulização sendo } \\
\text { utilizados de forma eficaz? }\end{array}$} \\
\hline \multicolumn{11}{|l|}{$\begin{array}{l}\text { Os suínos permanecem na área de descanso } \\
\text { durante um periodo de } 2 \text { à } 4 \text { horas? }\end{array}$} \\
\hline $\begin{array}{l}\text { O tempo total de jejum dos suinos desde a } \\
\text { granja até o abate não ultrapassa } 18 \text { horas? }\end{array}$ & & & & & & & & & & \\
\hline
\end{tabular}

FIGURA 1. Formulário utilizado para anotações das observações de suínos realizadas ante-mortem, em um matadouro-frigorífico do Triângulo Mineiro, MG. 
Fonte: Ludtke et al. (2010a).

\section{RESULTADOS E DISCUSSÃO}

\section{Caracterização dos animais e registro de mortalidade}

Com relação à origem dos suínos abatidos, 23,33\% eram procedentes do município de Passos, Minas Gerais (MG). Os demais procederam de Carmo do Paranaíba, Patrocínio, Perdizes, Presidente Olegário, Santa Juliana, Santa Vitória, São José da Barra e Varjão de Minas (MG), cujas frequências podem ser observadas na tabela 1. Dentre os locais de origem, o município mais próximo ao de Uberlândia (MG) é o de Santa Juliana com cerca de 100 quilômetros de distância. Já São José da Barra corresponde ao local mais distante, com aproximadamente 385 quilômetros de distância. A chegada dos veículos ao abatedouro-frigorífico foi registrada entre $00 \mathrm{~h} 40 \mathrm{~min}$ e $22 \mathrm{~h} 40 \mathrm{~min}$.

TABELA 1. Quantidade de lotes e de animais (\%) observados, em relação ao município de origem dos suínos, antes de serem abatidos em um abatedourofrigorífico do Triângulo Mineiro, MG.

\begin{tabular}{lcc}
\hline Origem & Quantidade de lotes & Quantidade de animais (\%) \\
\hline Carmo do Paranaiba & 02 & 6,66 \\
Passos & 07 & 23,33 \\
Patrocínio & 05 & 16,66 \\
Perdizes & 05 & 16,66 \\
Presidente Olegário & 04 & 13,33 \\
Santa Juliana & 03 & 10 \\
Santa Vitória & 01 & 3,33 \\
São José da Barra & 02 & 6,66 \\
Varjão de Minas & 01 & 3,33 \\
Total & 30 & 100 \\
\hline
\end{tabular}

Dos 5.389 animais analisados, sete $(0,13 \%)$ chegaram mortos. Nas pocilgas ocorreram quatro mortes $(0,07 \%)$, sendo $11(0,2 \%)$ a totalidade de animais mortos durante o transporte e nas pocilgas. No que se diz respeito à ocorrência de mortes durante o transporte, verificou-se que do total de 30 veículos que realizaram o transporte, cinco chegaram com suínos mortos (16,66\%). A distância das granjas de procedência dos lotes até o abatedouro-frigorífico analisados foi de no mínimo 100 $\mathrm{km}$. O percentual de animais que chegaram mortos $(0,13 \%)$ foi menor que o encontrado em outra pesquisa de González et al. (2006) que mostraram uma percentagem de $(0,46 \%)$ de suínos mortos durante 0 transporte quando transportados por distâncias superiores a $100 \mathrm{~km}$, e $(0,21 \%)$ quando transportados por $50 \mathrm{~km}$.

A tabela 2 indica que o município de Passos foi o que apresentou maior porcentagem de animais mortos em um único lote $(1,66 \%)$, além disso, foi o município que registrou maior número de animais mortos por veículo durante a avaliação, sendo que dos sete veículos provenientes desse local, dois chegaram com animais mortos $(28,57 \%)$. 
TABELA 2. Correlação da quantidade total de suínos por município de origem, e quantidade absoluta e percentual de animais que chegaram mortos por município em um abatedouro-frigorífico do Triângulo Mineiro, MG.

\begin{tabular}{lcc}
\hline Origem & Quantidade de suínos & Quantidade de mortes \\
\hline Passos & 120 & $02(1,66 \%)$ \\
Presidente Olegário & 200 & $01(0,5 \%)$ \\
Patrocínio & 240 & $01(0,42 \%)$ \\
Santa Juliana & 160 & $02(1,25 \%)$ \\
São José da Barra & 240 & $01(0,42 \%)$ \\
Total & 960 & $07(0,73 \%)$ \\
\hline
\end{tabular}

Segundo informações obtidas junto ao Serviço de Inspeção Oficial permanente no estabelecimento, a causa de todas as mortes foi por estresse agudo durante o transporte, associado, em algumas ocasiões, às altas temperaturas ambientais. Para diminuir o estresse térmico, recomenda-se que o transporte seja feito nas horas mais frescas do dia de preferência durante a noite ou nas primeiras horas da manhã (BISPO et al., 2016), o que não foi realizado no estabelecimento analisado, em que 22 veículos $(73,33 \%)$ transportaram os animais nas horas mais quentes do dia e somente oito veículos $(26,66 \%)$ fizeram o transporte na horas mais frescas.

Além disso, a densidade adequada durante o transporte pode evitar mortes e lesões significativas na carcaça. Segundo a Comissão Europeia, para um animal de $100 \mathrm{~kg}$ de peso vivo, é necessário $0,425 \mathrm{~m}^{2}$ ou $235 \mathrm{~kg} / \mathrm{m}^{2}$, sendo que dependendo do tempo de transporte e temperatura, esse número pode variar $20 \%$ chegando a 0,510 ou $196 \mathrm{~kg} / \mathrm{m}^{2}$. Quanto ao tipo de condução, o motorista deve ter o conhecimento de boas práticas de transporte que garantam o bem-estar dos suínos, com atenção, para que nada afete negativamente esse bem-estar (LUDTKE et al., 2016a).

\section{Manejo no desembarque}

Verificou-se no presente estudo que $100 \%$ dos lotes de suínos foram desembarcados imediatamente após a chegada ao abatedouro-frigorífico, prática recomendada para minimizar o estresse dos animais advindo do transporte (DALLA COSTA; DALLA COSTA, 2014). Porém, no desembarque, o bastão elétrico foi usado em todos dos lotes avaliados. Segundo a Instrução Normativa $n^{\circ} 03 / 2000$ do (MAPA), que trata dos métodos de insensibilização e de procedimentos de manejo pré-abate para o abate humanitário de animais de açougue (BRASIL, 2000), a movimentação dos animais deve ser realizada com o mínimo de excitação e desconforto, sendo proibido qualquer ato ou uso de instrumentos que prejudiquem a integridade física dos animais ou provoque reações de aflição.

Embora o uso de bastão elétrico seja permitido, este só deve ser utilizado em animais que se recusarem a mover continuamente e quando outros métodos falharem, desde que as descargas elétricas sejam feitas somente nos locais indicados, por até dois segundos e que haja espaço o suficiente para que os animais avancem. Recomenda-se o uso de chocalhos, ar comprimido e prancha de manejo que estimulam a movimentação do animal sem estressá-lo ou prejudicar a integridade física (DALLA COSTA; DALLA COSTA, 2014). 
Segundo os responsáveis pelo estabelecimento, é disponibilizado e permitido o uso do bastão elétrico no desembarque dos animais. O uso sem critério do bastão elétrico e falta de treinamento adequado, acarretam em mais lesões nos animais. Essa situação foi relatada por Ludtke et al. (2010b), que após avaliar um total de 120 suínos, distribuídos em dois grupos de 60 animais (grupo 1 - manejados sem o uso do bastão elétrico e grupo 2 - manejados com o uso do bastão elétrico), constatou que no grupo em que os suínos foram manejados com o uso do bastão elétrico houve um grande percentual $(57,69 \%)$ de lesões na região da paleta, atribuídas à sua utilização.

\section{Densidade das pocilgas de descanso e disponibilidade de água}

Após a acomodação dos animais analisados, verificou-se que todas as pocilgas de descanso, estavam com a densidade adequada. Segundo Ludtke et al. (2016b), deve haver espaço suficiente nas pocilgas para que todos os suínos deitem, caminhem e tenham acesso livre ao bebedouro, sendo que para isso é recomendado a densidade de $0,60 \mathrm{~m}^{2} / 166 \mathrm{~kg} / \mathrm{m}$ no mínimo para suínos de $100 \mathrm{~kg}$. Verificou-se neste trabalho que esta recomendação foi plenamente atendida, visto que o responsável pela acomodação dos animais nas pocilgas possui treinamento adequado para tal função.

No que diz respeito à disponibilidade de água, a Portaria 711 do MAPA (BRASIL, 1995), determina a existência de água limpa em quantidade suficiente para permitir que $15 \%$ dos suínos tenham acesso simultâneo ao bebedouro durante todo período de descanso. Portanto, recomenda-se que para cada sete animais haja um bebedouro disponível com vazão de dois litros por minuto (LUDTKE et al., 2016b). No presente estudo, apenas um dos 30 lotes analisados, contendo 41 suínos $(3,33 \%)$, foi alocado em uma pocilga composta por cinco bebedouros, que possibilitava o acesso aos mesmos por $12 \%$ dos animais em média.

As pocilgas do abatedouro-frigorífico avaliado têm entre cinco a 10 bebedouros, sendo que cada uma recebe em média 30 a 35 suínos por vez. Segundo informações da Médica Veterinária do Serviço de Inspeção Oficial do estabelecimento, a ocorrência do lote fora dos parâmetros impostos acontece raramente, pois os suínos são bem distribuídos nas pocilgas logo após o desembarque pelo manejador responsável.

\section{Tempo de descanso e conforto térmico}

No ambiente da área de descanso, deve ser promovido conforto térmico aos animais, com sombreamento, ventilação e nebulização utilizados de maneira eficaz. Durante o período estudado, não foi verificada a presença de ventilação e nebulização, que promovessem o conforto térmico dos suínos em épocas quentes, sendo que apenas o sombreamento era disponibilizado. De acordo com Ludtke et al. (2016b), a nebulização é indicada quando há temperatura muito elevada $\left(>20^{\circ}\right)$ e umidade relativa do ar abaixo de $80 \%$, sendo utilizada apenas por 30 minutos após a chegada dos animais no abatedouro e durante 30 minutos que antecedem o abate. Os animais devem ser monitorados para que não haja uma queda brusca de temperatura, o que pode ocasionar hipotermia, acarretando sofrimento, presença de tremores musculares e elevando a ocorrência de anomalias da carne do tipo DFD.

A temperatura recomendada da área de descanso é de $15^{\circ} \mathrm{C}$ a $18^{\circ} \mathrm{C}$ e umidade relativa entre $59 \%$ e $65 \%$, somando-se a um período de descanso curto e uma ventilação eficiente, o que resultará em menor estresse aos animais e menor 
perda na qualidade da carne (LUDTKE et al., 2016b). Embora o estabelecimento do presente estudo não dispor destes artifícios, é recomendável o investimento na aquisição dos mesmos, e seu uso deve ser adequado.

Segundo Ludtke et al. (2010a), a permanência na área de descanso acima de quatro horas, reduz o bem estar dos animais. Dos 30 lotes avaliados, no presente estudo, apenas dois $(6,66 \%)$ não ultrapassaram esse período de descanso, sendo provenientes dos municípios de Passos e São José da Barra respectivamente. Machado et al. (2014) também salientaram aumento na temperatura de carcaça quando os animais têm maior tempo de descanso.

O tempo total de jejum dos suínos desde a granja até o abate foi calculado com base de registro no boletim sanitário que acompanha cada lote. Neste está registrado o horário da retirada de alimentos de cada lote. Com isso, calculou-se a diferença entre a hora do início do abate com a hora da retirada da alimentação de cada lote, obtendo-se o tempo total de jejum. Apenas três (10\%) dos 30 lotes não ultrapassaram 18 horas sem alimentação, valor máximo preconizado por Ludtke et al. (2010a), enquanto os 27 lotes (90\%) restantes extrapolaram 18 horas de jejum. A Portaria 711/1995 (BRASIL, 1995) estabelece 24 horas como tempo máximo de jejum para os suínos, sendo que, se esse período for ultrapassado, os mesmos deverão ser alimentados e posteriormente serem submetidos a um novo período de jejum, para que possa proceder, o abate dos mesmos.

\section{Uso do bastão elétrico na entrada do restrainer}

Verificou-se que $26,01 \%$, dos suínos foram conduzidos sem uso de bastão elétrico na entrada do restrainer; $1,85 \%$, dos suínos foram conduzidos com bastão elétrico sem motivo aparente e $72,13 \%$ com bastão elétrico quando esses se negavam a mover-se (Tabela 3).

TABELA 3. Quantidade absoluta e percentual de suínos conduzidos na entrada do restrainer, de acordo com o uso de instrumento, em um abatedouro-frigorífico de suínos do Triângulo Mineiro, MG.

\begin{tabular}{lc}
\hline Condução de suínos na entrada do restrainer & Quantidade de animais \\
\hline Sem o uso do bastão elétrico & $1402(26,01 \%)$ \\
Com o uso de bastão elétrico sem motivo aparente & $100(1,85 \%)$ \\
Com o uso de bastão elétrico quando se negavam & $3887(72,13 \%)$ \\
a movimentar & 0 \\
Com instrumento contundente & $5389(100 \%)$ \\
Total & \\
\hline
\end{tabular}

No abatedouro-frigorífico em que se avaliou o uso do bastão elétrico, este instrumento foi utilizado acima do percentual recomendado pela WSPA (até $25 \%$ do número total de animais). Sendo que, a utilização de bastão elétrico além de causar dor, estresse e lesões na carcaça, reflete diretamente na qualidade da carne (LUDTKE et al., 2010b). 


\section{CONCLUSÕES}

As condições de manejo pré-abate que contemplam a chegada e permanência dos suínos nas áreas de descanso, além da condução para a sala de abate, em um abatedouro-frigorífico localizado no Triângulo Mineiro revelaram-se satisfatórias em sua maioria. Alguns pontos a serem melhorados foram identificados, como o uso excessivo de bastão elétrico, optando-se por métodos que ocasionam menor estresse aos animais e adoção de equipamentos de nebulização e ventilação, a fim de proporcionar maior conforto térmico nos momentos necessários.

\section{REFERÊNCIAS}

AMI FOUNDATION. Recommended animal handling guidelines \& audit guide: a systematic approach to animal welfare. 2010. Disponível em: $<$ http://www.animalhandling.org/ht/d/sp/i/26752/ pid/26752>. Acesso em: 20 jul. 2016.

BISPO, L. C. D.; ALMEIDA, E. C.; DIAS, F. J. S.; LOPES, K. L. A. M.; VALENTE, A. L. S. Bem-estar e manejo pré-abate de suínos: Revisão. PUBVET, v. 10, p. 795-872, 2016.

BRASIL. Ministério da Agricultura, Pecuária e Abastecimento. PORTARIA № 711, DE 1- DE NOVEMBRO DE 1995. Aprova as normas técnicas de instalações e equipamentos para abate e industrialização de suínos. Diário Oficial da União, Brasília, DF, de 3 nov.1995.

BRASIL. Ministério da Agricultura e do Abastecimento. INSTRUÇÃO NORMATIVA № 3, DE 17 DE JANEIRO DE 2000. REGULAMENTO TÉCNICO DE MÉTODOS DE INSENSIBILIZAÇÃO PARA O ABATE HUMANITÁRIO DE ANIMAIS DE AÇOUGUE. Diário Oficial da União, Brasília, DF, de 17 jan. 2000.

CORREA, J. A.; TORREY, S.; DEVILLERS, N.; LAFOREST, J. P.; GONYOU, H. W.; FAUCITANO, L. Effects of different moving devices at loading on stress response and meat quality in pigs. Journal of Animal Science, v. 88, p.4086-4093, 2010.

DALLA COSTA, O. A.; COSTA, M. J. R. P; LUDKE, J. V.; COLDEBELLA, A.; KICH, J. D.; PELOSO, J. V.; FAUCITANO, L.; ROZA, D. D. Tempo de jejum dos suínos no manejo pré-abate sobre a perda de peso corporal, o peso do conteúdo estomacal e a incidência de úlcera esofágica-gástrica. Ciência Rural, Santa Maria, v. 38, n. 1, p. 199-205, jan-fev, 2008.

DALLA COSTA, O. A.; DALLA COSTA, F. A., CARDOSO, L. S. Equipamentos de manejo pré-abate dos suínos. Concordia: Embrapa Suínos e Aves-Comunicado Técnico, 513. 6 p., 2013.

DALLA COSTA, F. A.; DALLA COSTA, O. A. Preparo dos animais para o transporte. In: Associação Brasileira dos Criadores de Suínos (Coordenação editorial). Manual de Industrialização dos Suínos. Brasília, DF: Associação Brasileira dos Criadores de Suínos, p.73-90, 2014. 
FAUCITANO, L.; ROCHA, M. R. Poderiam as últimas 24 horas pré-abate influenciar a qualidade da carne suína?. Bem estar animal como valor agregado nas cadeias produtivas de carnes, p. 47-56, 2016. Disponível em URL: http://www.grupoetco.org.br/arquivos_br/pdf/Bem-estar-animal-como-valoragregado.pdf. Acesso em: 24 de Janeiro de 2019.

FELÍCIO, P. E. O ABC do PSE/DFD. Aliment. Tecnol., v. 2, n. 10, p. 54-57, 1986.

GONZÁlEZ, M.; AVERÓS, X.; VALDELVIRA, J.J; HERRANZ, A. Influence of season, distance and mixed loads on the physical and carcass integrity of pigs transported to slaughter. Meat Science, v.73, p.553- 558, 2006.

HOCQUETTE, J. F., BOTREAU, R., LEGRAND, I., POLKINGHORNE, R., PETHICK, D. W., LHERM, M., PICARD B., DOREAU M., TERLOUW, E. M. C. Win-win strategies for high beef quality, consumer satisfaction, and farm efficiency, low environmental impacts and improved animal welfare. Animal Production Science, v. 54, n. 10, p. 1537-1548, 2014.

LENGERKEN, G.; MAAK, S.; WICKE, M. Muscle metabolism anda meat quality of pigs and poultry. Veterinrija Ir Zootechinika, v. 42, p. 82-86, 2002.

LUDTKE, C. B.; CIOCCA, J. R. P.; DANDIN, T.; BARBALHO, P. C.; VILELA, J. A.; DALLA COSTA, O. A. Abate Humanitário de Suínos. Manual WSPA. Rio de Janeiro, Brasil, 132 p., $2010 a$.

LUDTKE, C. B.; SILVEIRA, E. T. F.; BERTOLONI, W.; DE ANDRADE, J. C.; BUZELLI, M. L. T.; BRESSA, L. R.; SOARES, G. J. D. Bem-estar e qualidade de carne de suínos submetidos a diferentes técnicas de manejo pré-abate. Revista Brasileira de Saúde e Produção Animal, v. 11, n. 1, p. 231-241, 2010b.

LUDTKE, C.; PELOSO, J. V.; DALLA COSTA, O. A.; ROHR, S. A.; DALLA COSTA, F. A. Bem-Estar Animal na Produção de Suínos: Transporte. SEBRAE/ABCS. Brasília, DF. 38 p., 2016a. Disponível em: http://www.abcs.org.br/attachments/01_Cartilha2_bloq.pdf Acesso em: 23 de Jan. de 2019.

LUDTKE, C.; PELOSO, J. V.; DALLA COSTA, O. A.; ROHR, S. A; DALLA COSTA F. Bem-estar Animal na Produção de Suínos-Frigorífico. SEBRAE/ ABCS. BrasíliaDF, 46 p., 2016b. Disponível em: http://www.agricultura.gov.br/assuntos/boaspraticas-e-bem-estar-animal/arquivos-publicacoes-bem-estar-animal/cartilhaembrapa-abcs-mapa-sebrae-bem-estar-no-frigorifico.pdf. Acesso em: 25 de Jan. de 2019.

MACHADO, S. T.; SANTOS, R. C.; CALDARA, F. R.; GONÇALVES, M. C.; JORDAN, R. A.; DOS REIS, J. G. Operação de transporte e tempo de descanso na incidência de carne PSE em suínos. Revista Brasileira de Engenharia Agrícola e Ambiental, v. 18, p. 1065-1071, 2014. 
MOURA, J. W. F., DE MEDEIROS, F. M., ALVES, M. G. M., BATISTA, A. S. M. Fatores influenciadores na qualidade da carne suína. Revista Científica de Produção Animal, v. 17, n. 1, p. 18-29, 2015.

OFFICE INTERNATIONAL DES EPIZOOTIES (OIE). Terrestrial Animal Health Code. Vol. I. Chapter 7.1.: "Introduction to the recommendations for animal welfare", 2014. Disponível em: http://www.oie.int/index.php?id=169\&L=0\&htmfile=chapitre_aw_introduction.htm. Acesso em: 01 de Fev. De 2019.

SIONEK, B.; PRZYBYLSKI, W. 3. The Impact of Ante-and Post-Mortem Factors on the Incidence of Pork Defective Meat-A Review. Annals of Animal Science, v. 16, n. 2, p. 333-345, 2016.

WEBSTER, A. J. F. International standards for animal welfare: Science and values. Vet. J., n. 2-3, p. 198, 2003. 